\title{
"STOCKING OF FORESTS FROM AIR PHOTOGRAPHS”
}

\author{
By Hiroichi Nakayama, \\ Professor of Forest Managemant. Utsononiya Agricultural College, \\ Utsonomiya, Japan.
}

Sec. A. Vol. 2, No. 2, 1935, pp. 43-58.

$T$

7 HE forest has great area and volume, at the same time its value (per unit area) is relatively small, especially in undeveloped countries. For this reason in stock-taking (itself difficult) special methods must be employed. It is for this work that Air Survey is best suited, and recently various countries have taken up on a large scale this new means of investigating forests.

In Japan, during 1923 aerial photogrammetry came first into practical use. In that year, Tokyo was photographed for the purpose of preparing new maps, immediately following the great earthquake. Later the new method was frequently used for revising and augmenting information on existing maps, and for the survey of railway lines.

It was early recognized that Air Survey would play an important role in colonial forestry, but it was not till 1929 that aerial photography was applied to forestry purposes by the Japanese. A portion, 1100 h.a. $(2,720 \mathrm{ac}$.) of the state forest near Keijo in Korea was photographed (vertically) from the air. Forest officer. N. Kakeba carried out important research in the utility of air photos in stock-taking of forests, and found them very much to the purpose.

The next year a large survey was made in Sachalin, where an area of 640,000 h.a. $(1,580,000 \mathrm{ac}$.) of state forest was covered with vertical aerial photography, with $60 \%$ overlap and scale of $1: 15,000$. This project was so successful that in 1931 almost double the area, 1,010,000 h.a. $(2,500,000$ ac.), and in 1934 an additional 700,000 h.a. $(1,730,000$ ac.) were similarly photographed from the air; altogether $2,390,000$ h.a. $(5,900,000$ ac. $)$ or $70 \%$ of the Japanese Sachalin photographed for forestry purposes.

At the present time research in the stereoscopic compilation of these pictures for forestry purposes is being carried on, and in the meantime practical use is made of them for forest description (Species and forest types, volume estimates, and areas) selection and definition of various classes of land utilization; boundaries for forest management; and logging roads and railway location. Base-maps on a scale of $1: 25,000$ are prepared from photos by graphic methods.

In Germany, topographic mapping and stock-taking of forest from air photos have been tried out by various methods using stereo-plotting machines, 
STOCKING OF FORESTS FROM AIR PHOTOGRAPHS 49

e.g. the Autokartograph, Aerokartograph, and the Zeiss Stereoplanigraph; very important results have been achieved.

In Japan the new methods using the stereoplotting machine have not yet been employed for pure forestry purposes, but they are of great importance not only for the more intensive forest areas of the Colonies, but also for those forests in the old countries where suitable forest maps are not yet available. The new methods can be directly applied to management plan surveys. However, the use of aerial photographs in conjunction with the stereoplotting machines for forest volume determination will necessitate investigation of several computing coefficients, or conversion factors.

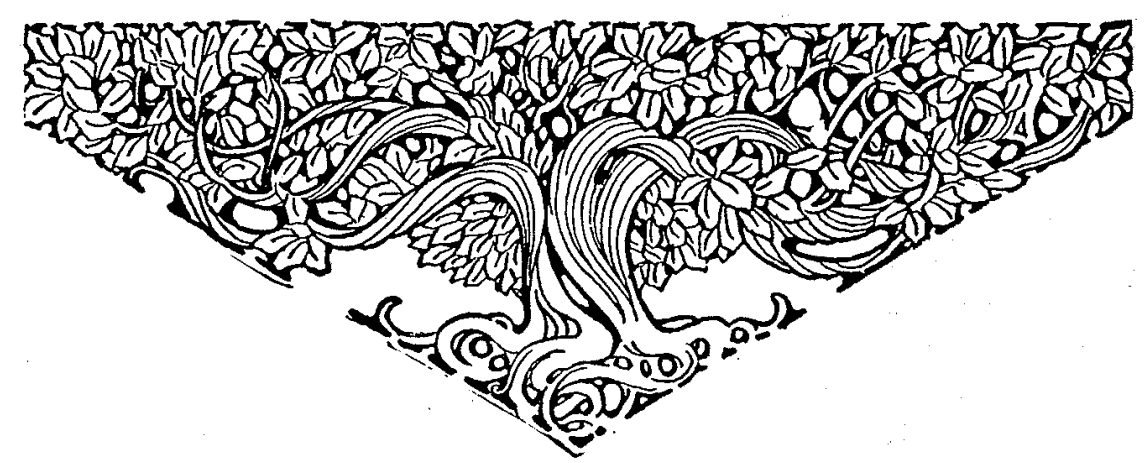

